\title{
Atrofia progressiva generalizada da retina em cães da raça Cocker Spaniel
}

\author{
Generalized progressive retinal atrophy in Cocker Spaniel dogs
}

Débora Gomes $^{\mathrm{I}^{*}}$ Denise Aya Otsuki $^{\mathrm{II}}$ Ricardo Lisak ${ }^{\mathrm{I}}$ Angélica de Mendonça Vaz Safatle ${ }^{\mathrm{I}}$

\section{- REVISÃO BIBLIOGRÁFICA -}

\section{RESUMO}

Atrofia progressiva generalizada da retina (APGR) é uma doença frequente nos cães da raça Cocker Spaniel, caracterizada pela perda progressiva da função retiniana externa e desaparecimento dos fotorreceptores. A doença é bilateral, hereditária, autossômica recessiva, sem predisposição sexual e está frequentemente associada à catarata. Segundo estudos moleculares, a degeneração ocorre por mutação de diversos genes. Nos cães da raça Cocker Spaniel Americano, a doença é observada entre três e cinco anos de idade e, no Cocker Spaniel Inglês, entre quatro e oito anos de idade. Os sinais clínicos mais encontrados são: nictalopia, hiperreflexia tapetal e catarata. $O$ diagnóstico baseia-se no histórico clínico, exame oftalmológico e em exames complementares, como eletrorretinograma, testes genéticos e ultrassom ocular. Este artigo teve como objetivo realizar uma revisão de literatura a respeito da atrofia progressiva generalizada da retina (APGR) em cães da raça Cocker Spaniel portadores de catarata.

Palavras-chave: retina, Cocker Spaniel, catarata, degeneração retiniana. ABSTRACT

Generalized progressive retinal atrophy (GPRA) is a common disease in Cocker Spaniels dogs characterized by progressive loss of retinal function and disappearance of photoreceptors. The disease is bilateral, hereditary, autosomal recessive, has no sexual predisposition and is frequently associated with cataracts. According to molecular studies the degeneration occurs by a mutation in different genes. In American Cocker Spaniels dogs the disease is observed between three and five years of age and in English Cocker Spaniels between four and eight years old. The clinical signs are: nyctalopia, tapetal hyperreflexia and cataracts. The diagnosis is based on clinical history, ophthalmologic examination and complementary exams such as electroretinography, ocular ultrasound and genetic testing. This article aimed to conduct a review of literature on the generalized progressive retinal atrophy (GPRA) in Cocker Spaniel dogs with cataracts.

Key words: retinal, Cocker Spaniels, cataract, retinal degeneration.

\section{INTRODUÇÃO}

As degenerações retinianas no cão incluem: atrofia progressiva generalizada da retina (APGR), distrofia do epitélio pigmentado da retina (atrofia progressiva central da retina), cegueira noturna estacionária congênita e distrofia de cones (LIN et al., 2002).

Atrofia progressiva generalizada da retina (APGR) é uma desordem bilateral e hereditária autossômica recessiva (MELLERSH, 2012). Tal desordem faz parte de um grupo de doenças degenerativas primárias dos fotorreceptores, que se manifestam prematuramente na forma de displasias e tardiamente na forma de distrofias, resultando em sinais clínicos similares e, por fim, em cegueira (PETERSEN-JONES, 1998; GELATT, 2003). Nos cães da raça Cocker Spaniel Inglês e Americano, a doença ocorre por uma distrofia dos fotorreceptores (CÔCO et al., 2009). Clinicamente, observa-se midríase bilateral com perda da visão noturna (nictalopia) e posteriormente perda da visão diurna (acromatopsia) (MIYADERA et al., 2012).

Os cães da raça Cocker Spaniel portadores de catarata apresentam com alta frequência

IClinica Vetmasters, Rua Bela Cintra, 1500, Jardins, 01415-000, São Paulo, SP, Brasil. E-mail: debbgomes@usp.br. *Autor para correspondência.

IFFaculdade de Medicina, Universidade de São Paulo (USP), São Paulo, SP, Brasil. 
eletrorretinograma de campo total (ERG), compatível com diagnóstico de degeneração retiniana (SAFATLE et al., 2010a). A catarata pode ser atribuída às lesões oxidativas das proteínas e lipídios que protegem a lente (BARROS et al., 1999; DENNIS et al., 2003; LAUS, 2007).

Com base nessas informações, o presente estudo teve como objetivo fazer uma revisão de literatura a respeito da doença em cães da raça Cocker Spaniel Ingleses e Americanos.

Etiologia e Fisiopatogenia da atrofia progressiva generalizada da retina

Atrofia progressiva generalizada da retina é uma doença genética, de caráter autossômico recessivo, que pode acometer cães da raça Cocker Spaniel (MIYADERA et al., 2012). Resulta em perda progressiva da função retiniana externa e morte dos fotorreceptores bilateralmente, tendendo à simetria e sem predisposição sexual (BEDFORD, 2005; TUNTIVANICH et al., 2009). Outras causas de APGR podem estar relacionadas à deficiência nutricional, glaucoma, inflamação, isquemia e toxinas (MILLICHAMP, 1990). A nictalopia (cegueira noturna) é o primeiro sinal observado, uma vez que há o acometimento inicial de bastonetes e posteriormente de cones, que culmina em cegueira diurna (KARLSTAM et al., 2011; NARFSTRÖM et al., 2011).

A mutação genética foi descoberta por ZANGERL et al. (2006) e AGUIRRE-HERNANDEZ et al. (2007). Nesses estudos, os autores observaram que a mutação ocorre no segundo códon onde a base nitrogenada guanina é substituída por adenina (Tiamina-Guanina-Citosina - TGC para TiaminaAdenina-Citosina - TAC).

Outras alterações observadas ao exame clínico estão relacionadas aos reflexos pupilares, que se tornam lentos à luz, mas podem estar presentes até determinado grau da doença, inclusive em estágios avançados (YOGO et al., 2011). A perda da visão, em geral, é acelerada pela presença de catarata secundária (MAEHARA et al., 2007). As alterações iniciais surgem nas áreas corticais posteriores do cristalino, evoluindo para opacidade total (BEDFORD, 2005).

À oftalmoscopia, observa-se atenuação vascular, palidez de papila, hiperreflexia da área tapetal pelo afinamento da retina e despigmentação da área não-tapetal. A área mais afetada é a região periférica da retina, sendo a região inferior mais acometida que a superior (BEDFORD, 2005).

Histologicamente, a primeira mudança identificável é o aparecimento de vesículas na porção externa dos fotorreceptores. Posteriormente, observase que o segmento externo dos bastonetes apresenta lamelas desorganizadas e desordenadas (CLEMENTS et al., 1996). Há perda focal com reorganização da membrana limitante externa e invasão do epitélio pigmentado da retina por macrófagos. Os sinais dependem do estágio da degeneração, nos estágios avançados há adegalçamento vascular e despigmentação da área tapetal. Em estágios moderados, nota-se alteração bem delimitada ou gradual entre as áreas tapetal normais e degeneradas e, em particular, na periferia. Nas alterações iniciais, observam-se mudanças sutis na coloração tapetal periférica, os vasos apresentam diâmetro atenuado, principalmente os vasos periféricos, e a área não tapetal e o disco óptico podem ter aspecto normal (RIIS, 2005).

As mudanças eletrorretinográficas representam disfunção e morte celular na retina (KARLSTAM et al., 2011). O eletrorretinograma de campo total revela diminuição progressiva da amplitude pico a pico (pico da onda-a, primeira onda negativa registrada, gerada pelos fotorreceptores, ao pico da onda-b, onda positiva registrada em seguida da onda-a, resultante da ativação das células de Müller e, em menor significância, das células bipolares e indiretamente as camadas médias da retina) e aumento do tempo de culminação da onda-b, representada pela onda registrada desde o início do estímulo luminoso até o pico máximo dessa onda, sendo que a fase escotópica do exame é mais precocemente afetada, pois a função dos bastonetes é perdida mais rapidamente (NARFSTRÖM \& EKESTEN, 1998).

A doença manifesta-se clinicamente em cães da raça Cocker Spaniel Inglês entre quatro e oito anos de idade, enquanto em cães da raça Cocker Spaniel Americano são observadas alterações em média entre três a cinco anos de vida. Esses cães geralmente ficam cegos vinte e quatro meses após o diagnóstico da doença (CLEMENTS et al., 1996). No entanto, devido à possível preservação de ilhas de cones na retina, alguns animais podem apresentar visão diurna mesmo em estágios avançados da doença. Entretanto, com a progressão da doença, evoluem para cegueira (NARFSTRÖM, 2002).

\section{Diagnóstico}

O diagnóstico se baseia na história clínica completa e exame oftalmológico minucioso. No exame oftalmológico, são avaliados os reflexos pupilares diretos e consensuais, reflexo de ofuscamento, teste de ameaça e o segmento posterior é examinado com auxílio de oftalmoscopia direta e 
indireta. Em pacientes em que há opacidade de meios, o segmento posterior é avaliado por ultrassom ocular e eletrorretinograma (WEICHSLER, 2007).

A presença do reflexo pupilar direto e consensual não caracteriza função retiniana normal. Deve-se ter cautela ao avaliar esses reflexos, pois, mesmo estando presentes, a retina pode estar degenerada (GROZDANIC et al., 2006). O reflexo de ofuscamento, manifestado por um piscar de olhos, é mais preciso para avaliar a função retiniana, pois, quando existe lesão retiniana grave, lesão do disco óptico ou do nervo facial, esse reflexo está ausente (BOBOFCHACK et al., 2005).

Outro teste utilizado para avaliar a função retiniana é o teste de ameaça, que consiste em fazer um movimento próximo aos olhos do paciente. $\mathrm{O}$ examinador deve observar se o paciente responde com um piscar de olhos ou movimento de cabeça. É um teste consciente e acredita-se que seja uma resposta voluntária, pois pode estar ausente em alguns filhotes visuais (WEICHSLER, 2007).

O segmento posterior deve ser examinado com auxílio da oftalmoscopia direta e indireta em sala escura (WEICHSLER, 2007). O exame, dependendo da opacidade de meios, avalia tamanho, forma e coloração do disco óptico. Deve-se examinar a vasculatura retiniana, avaliando número, calibre e distribuição dos vasos. Se os vasos coroidais forem visíveis, estes também devem ser observados (figura 1). A área tapetal é avaliada quanto à refletividade, se está atenuada ou aumentada, e a área não-tapetal é avaliada quanto à pigmentação (GELATT, 2003). O médico veterinário deve procurar pelos sinais relatados ou por alterações na retina que justifiquem a baixa da visão. Na APGR, há mudanças de coloração, refletividade aumentada da área tapetal, pigmentação sobre ela, perda de pigmento ou pigmentação anormal em área não-tapetal (SLATTER, 2005).

Em casos de APGR, o tamanho do disco é menor e possui coloração esbranquiçada ou cinzapálida, pois os capilares do disco óptico estão diminuídos. A lâmina crivosa tem aparência de renda e pode ser identificada se a atrofia estiver avançada (MILLICHAMP, 1990).

\section{Exames complementares}

Eletrorretinografia

A eletrorretinografia consiste na estimulação da retina pela luz e no registro de sua resposta. Luz de intensidade, comprimentos de onda e duração de flashes variáveis são direcionados à superfície da córnea (HONSHO et al., 2004). O exame registra onda elétrica que corresponde à diferença de potencial capturado pelos eletrodos ativo monopolar (que pode ser em forma de lente de contato colocado sobre a córnea no caso do erg-jet, ou de microfibra

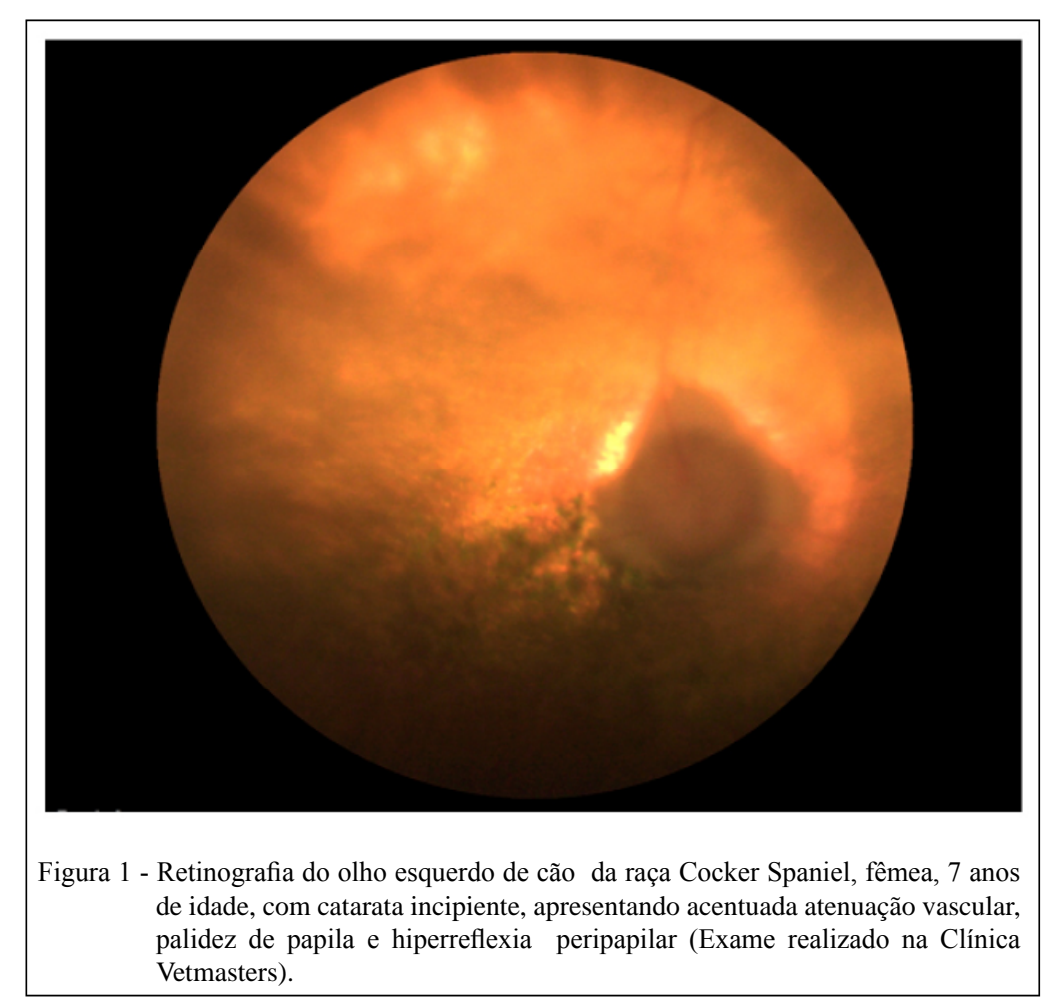

Ciência Rural, v.43, n.8, ago, 2013. 
como o modelo DTL) e de referência (eletrodo em cúpula de ouro colocado no canto temporal do olho) ou bipolar (Burian Allen, Gold lens) (BIRCH \& ANDERSON, 1992; SAFATLE et al., 2010a; SAFATLE et.al., 2010b).

Por se tratar de exame objetivo e pouco invasivo, tem grande utilidade na avaliação préoperatória de pacientes com catarata madura, nos quais não é possível avaliar o fundo do olho (GRANITZ, 1994). Também pode ser utilizado como auxílio no diagnóstico de outras doenças que possam resultar em cegueira (KOMAROMY et al., 1998; TZEKOV \& ARDEN, 1999; OFRI, 2002).

A eletrorretinografia (ERG) de campo total, pela análise dos potenciais de ação, é empregada para avaliar a integridade funcional da retina, e não a capacidade visual. Cães com cegueira central podem apresentar ERG normal (WEICHSLER \& HERRERA, 2007). Os animais portadores de APGR apresentam baixa amplitude e aumento no tempo de culminação (Figuras 2, 3 e 4) ou ausência de respostas, resultando em ERG extinto (SAFATLE et al., 2010a).

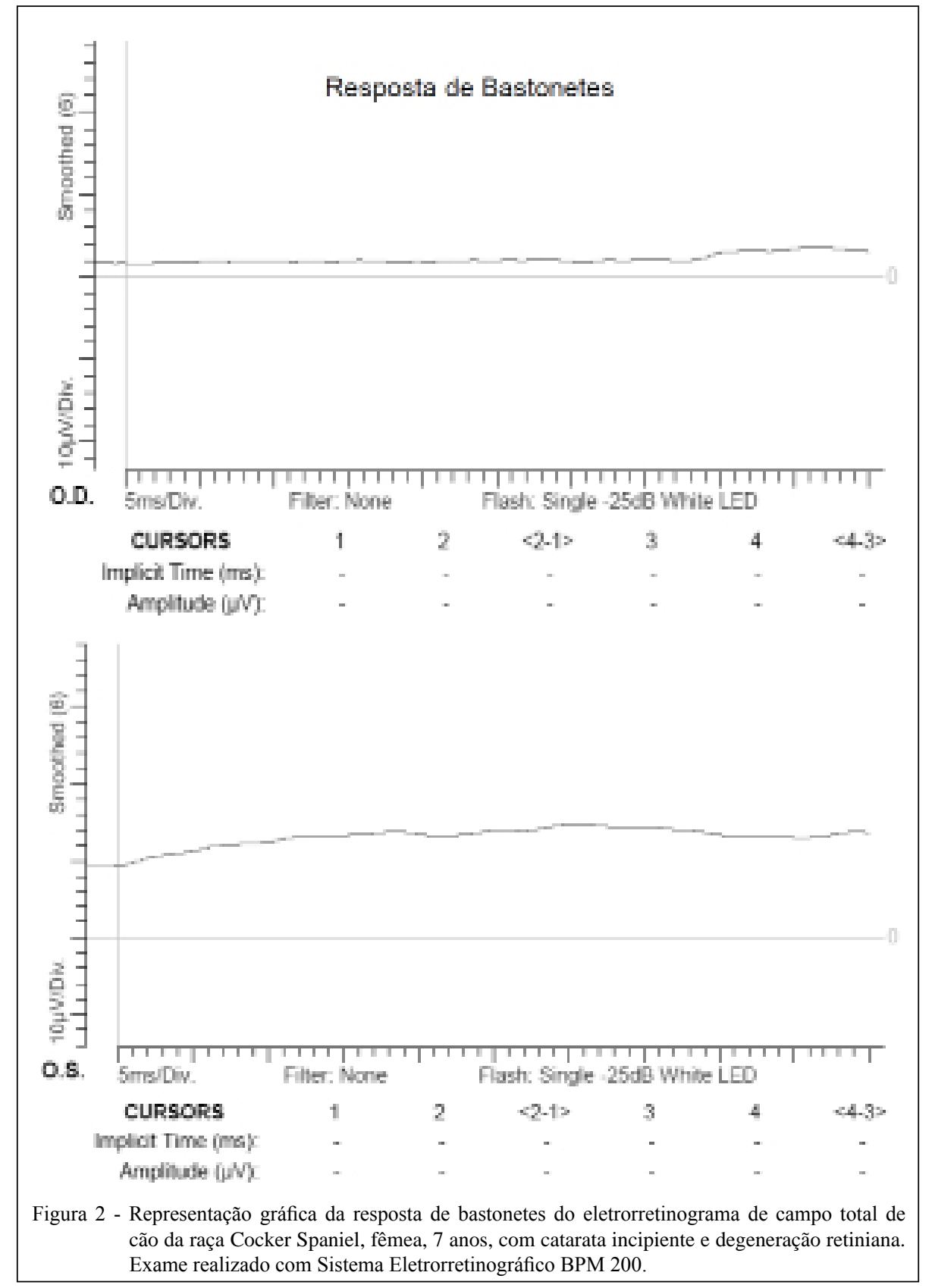

Ciência Rural, v.43, n.8, ago, 2013. 


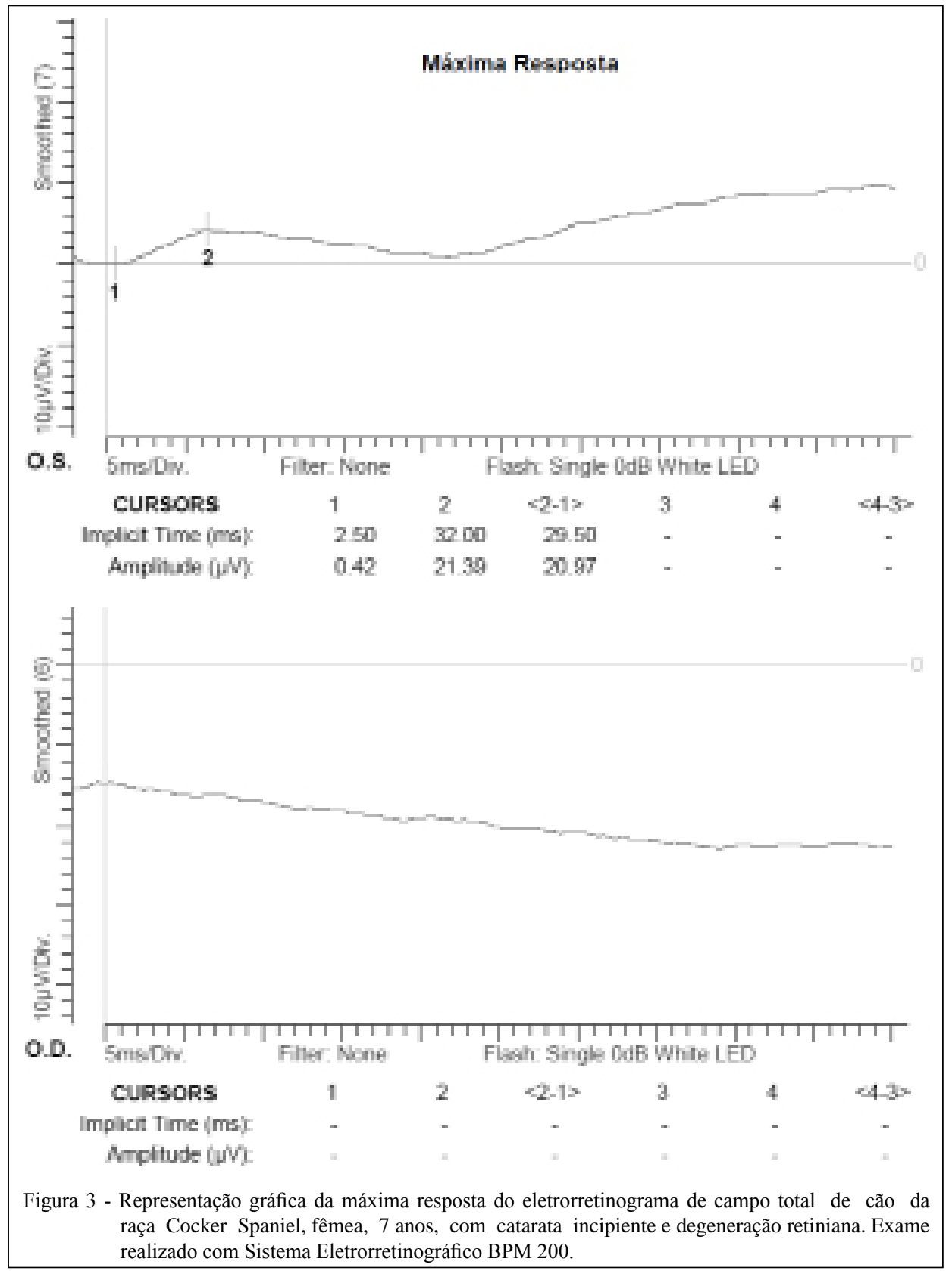

Ultrassom ocular

A ultrassonografia(US) ou ecografia ocular é um método de exame por imagem que utiliza ondas sonoras para avaliação de estruturas e alterações no bulbo ocular e na órbita (LUCENA et al., 2009). É um exame não invasivo, indicado para diagnóstico e acompanhamento de casos cujas opacidades de meios oculares impossibilitem a fundoscopia (QUINZE, 2005). O ultrassom ocular é importante para descartar outras alterações retinianas, como descolamento da retina (total ou parcial), exsudatos subretinianos, edema da retina ou ainda hemorragia vítrea (LUCENA et. al., 2009).

Testes genéticos

Os testes genéticos são exames laboratoriais que possibilitam a análise de DNA, RNA, cromossomos, proteínas e certos metabólitos do paciente, com o objetivo de detectar a presença de material genético, que pode estar (ou não) relacionado às doenças genéticas e hereditárias em geral (DEKOMIEN et al., 2010; MELLERSH, 2012).

Ciência Rural, v.43, n.8, ago, 2013. 


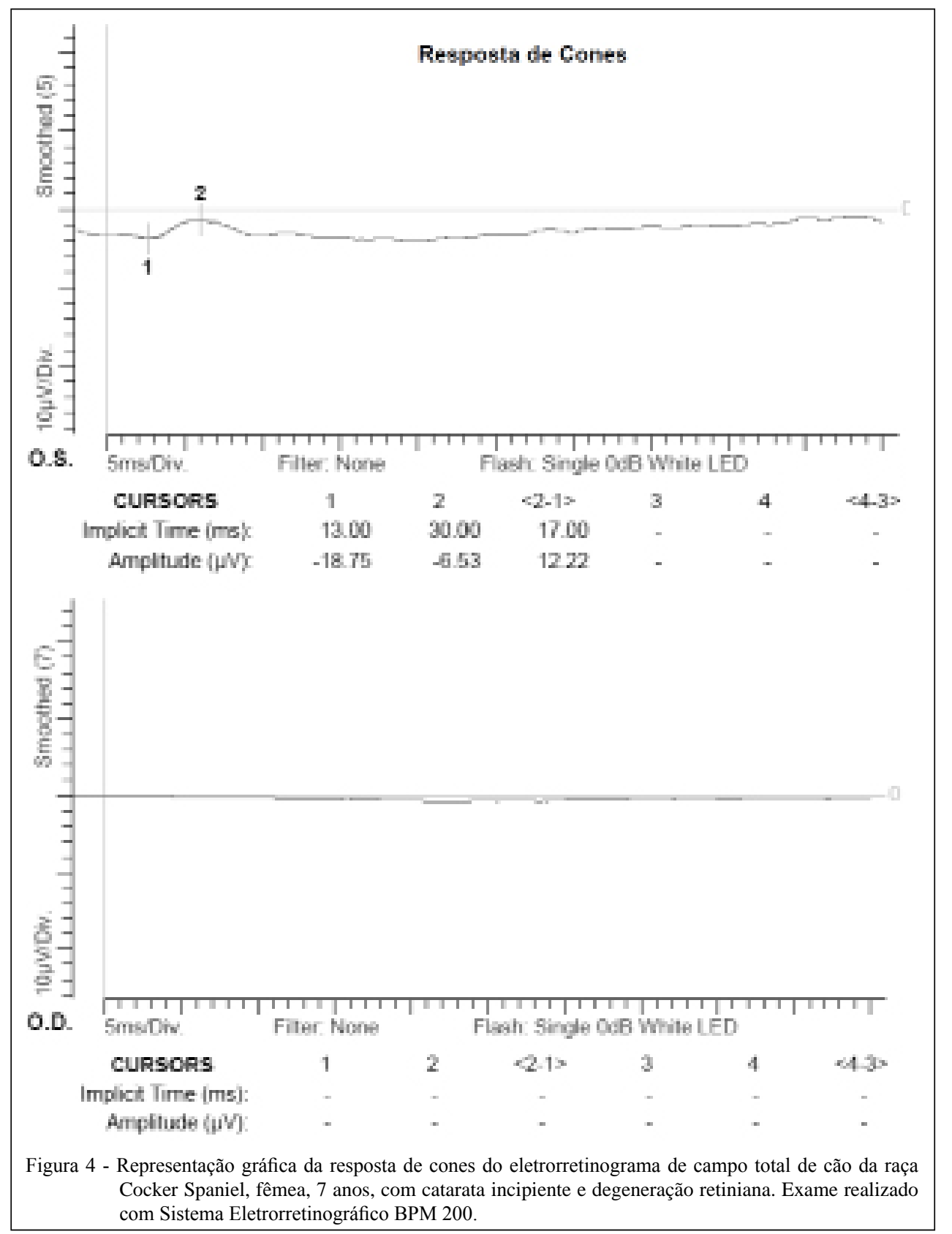

Diversas formas de degeneração retiniana são causadas por alterações genéticas. Com base nessas informações, desenvolvem-se testes específicos para cada alteração (FELIX, 2005).

A detecção da degeneração progressiva generalizada de cones e bastonetes nos cães da raça Cocker Spaniel é feito por marcador (uma sequência de nucleotídeos) no cromossomo 9 dos cães. O marcador genético é ligado aos cães que são clinicamente doentes, com o gene prcd para APGR (FELIX, 2005). A mutação é observada no segundo códon, onde, ao invés de TGC (timina-guaninacitosina), encontra-se TAC (timina-adenina-citosina) (TUNTIVANICH et al., 2009).

Assim sendo, esses testes determinam a probabilidade do cão ser acometido por atrofia progressiva generalizada da retina eérealizado utilizando uma pequena amostra de sangue. $\mathrm{O}$ resultado do teste revela a representação da constituição genética do indivíduo e permite a separação de cães em três grupos: normal (homozigoto normal), carreador (heterozigotos) e afetado (homozigoto mutante) (FELIX, 2005). 
Os testes de DNA não são realizados em nosso país e, por necessitarem de metodologia e equipamentos especializados, não são realizados na clínica particular. Os criadores que fazem uso desse teste genético enviam amostra de sangue para laboratório especializado em doenças oftalmológicas hereditárias, localizado no exterior (MELLERSH, 2012).

Diagnóstico diferencial

O diagnóstico diferencial é importante para descartar outras causas de baixa de visão. Esse diagnóstico, em geral, é direcionado pelo histórico do paciente, considerando o início dos sintomas e evolução da doença. Além do exame oftalmológico clínico, os exames complementares, como eletrorretinograma e ultrassom ocular são úteis para avaliar a causa da baixa de visão. Esses exames permitem identificar se a baixa de visão está relacionada a uma alteração anatômica, como descolamento retiniano ou funcional, como nas degenerações retinianas em que a resposta pode estar atenuada ou extinta (SLATTER, 2005).

\section{Tratamento}

Recentes estudos acreditam que a terapia com suplemento vitamínico possa prevenir ou retardar a progressão da degeneração retiniana, mas não pode reverter danos já ocorridos. Para cães com ausência de visão, é improvável que o suplemento traga benefício. Acredita-se que o suplemento vitamínico diminua a incidência do estresse oxidativo fisiológico, causado pelo envelhecimento, pela exposição à luz ultravioleta e pelo metabolismo celular, além de retardar o estresse oxidativo, causado por doenças como a atrofia progressiva da retina, degeneração senil da retina, glaucoma, uveíte, catarata e diabetes mellitus (SANGIOVANNI \& CHEW, 2005; GUM et al., 2007; BARDEN et al., 2008; NAKAJIMA et al., 2008).

As células saudáveis se utilizam da produção de antioxidantes intracelulares naturais, como a glutationa, com objetivo de combater o estresse oxidativo. Dentre os antioxidantes, encontramos: vitaminas C e E, carotenoides, ácidos graxos e zinco. O extrato de uva é considerado melhor captador de radicais livres que a vitamina $\mathrm{C}$, já a luteína e zeaxantina são potentes carotenoides capazes de proteger a retina e diminuir a incidência de catarata. Os ácidos graxos ômega 3 , introduzidos por meio da dieta, são importantes para preservarem os pequenos vasos que irrigam o bulbo ocular, protegendo a retina. $\mathrm{O}$ zinco é necessário para a ação de mais de 100 enzimas e para as reações químicas da retina, portanto, acredita-se que tenha efeito de limitar o estresse oxidativo (CÔCO et al., 2009).
Alguns pesquisadores defendem a terapia gênica para pacientes com alguma funcionalidade da retina. Essa terapia tem como objetivo inserir material exógeno, com finalidade de recuperar a função de um gene. O gene pode ser introduzido na retina por injeção intravítrea, sub-retiniana e intracameral. Em geral, utilizam-se vetores virais para a transferência gênica, mas também podem ser utilizados vetores não virais, mecanismos físicos e químicos. Constituem vetores não virais as nanopartículas de DNA, revestidas de um polímero catiônico. Dentre os mecanismos físicos, existe a eletroporação em que pulsos elétricos alterados são aplicados nas células que estão em contato com uma solução de DNA plasmidial e a corrente gerada forma poros na superfície celular, facilitando a entrada do material genético na célula. Outro exemplo de método físico que podemos citar é a biobalística ou gene gun em que as microesferas de ouro ou tungstênio cobertas com DNA são aceleradas por um gás carreador que projeta essas esferas contra as células, promovendo a entrada do DNA no núcleo. Nos mecanismos químicos, ocorre interação entre um lipídeo catiônico ou polímero catiônico e o DNA. No processo químico, a carga positiva do complexo interage com o grupamento fostato do DNA e a internalização celular ocorre por endocitose. $\mathrm{O}$ vetor é degradado no citoplasma, deixando a molécula de DNA livre para entrar no núcleo (BELTRAN, 2009; AMADO et al., 2010; MORIMOTO et al., 2011; MOWAT et al., 2011; NARFSTRÖM et al., 2011a, NARFSTRÖM et al., 2011b).

Em cães com APGR, o intervalo de tempo entre os primeiros sinais observados até o estágio final (cegueira total) é variável. Alguns podem ficar totalmente cegos em poucos meses, outros podem reter limitada visão central até três ou quatro anos após início dos sintomas (GELATT, 2003).

O método de controle recomendado é a certificação de todo o plantel de reprodutores e a manutenção de um arquivo central dessas informações, para que possa ser acessado por veterinários, criadores e possíveis proprietários (MELLERSH, 2012). Cães com APGR não devem ser colocados no programa de reprodução e o controle é indispensável, pois há muitos portadores assintomáticos (MELLERSH, 2012).

\section{CONSIDERAÇÕES FINAIS}

Baseado na experiência clínica, os autores desta revisão ressaltam a importância do diagnóstico precoce dessa afecção nos cães da raça Cocker, por considerar este o melhor método de controle. Exames complementares para o auxílio diagnóstico podem 
ser necessários, tais como a eletrorretinografia, visto que, por tratar-se de doença hereditária que acomete grande número de cães portadores de catarata, a avaliação fundoscópica torna-se impossibilitada. Por avaliar a função retiniana e detectar precocemente alterações na sua funcionalidade, esse exame tem importância ímpar no controle desta afecção.

Os autores recomendam, ainda, que os criadores sejam criteriosos ao selecionar seus reprodutores, não permitindo que animais carreadores do gene da atrofia progressiva da retina façam parte do programa de reprodução. Vale salientar que os sinais clínicos se manifestam na vida adulta, quando a maioria dos animais já poderia ter reproduzido.

Após diagnóstico, o tratamento mais acessível é feito com suplementos vitamínicos, porém não se atinge o nível de excelência desejado, pois o sucesso dessa terapia limita-se ao retardo da progressão da lesão retiniana. Outros métodos de tratamento ainda têm caráter experimental, não fazendo parte da rotina oftalmológica.

\section{REFERÊNCIAS}

AGUIRRE-HERNÁNDEZ, J. et al. The finnish lapphund retinal atrophy locus maps to the centromeric region of CFA9. BMC Vet Res, n.3, p.14, 2007. Disponível em: <http://www. biomedcentral.com/1746-6148/3/14>. Acesso em: 09 set. 2011. doi:10.1186/1746-6148-3-14.

AMADO, D. et al. Safety and efficacy of subretinal readminstration of a viral vector in large animal to treat congenital blindness, Sci Transl Med, v.2, n.21, p.21ra16, 2010. Disponível em: <http://www. ncbi.nlm.nih.gov/pubmed/20374996>. Acesso em: 9 mar. 2012.

BARDEN, C.A. et al. The effect of grape polyphenols on oxidative stress in canine lens epithelial cells. Am J Vet Res, v.69, p.94-100, 2008 .

BARROS, P.S.M. et al. Antioxidant profile of cataractous English Cocker Spaniels. Vet Ophthalmol, v.2, n.2, p.83-86, 1999. Disponível em: <http://onlinelibrary.wiley.com/doi/10.1046/ j.1463-5224.1999.00056.x/abstract>. Acesso em: 9 mar. 2012. doi: 10.1046/j.1463-5224.1999.00056.x.

BEDFORD, P.G.C. Progressive retinal atrophy in dogs. Vet Record, v.156, n.4, p.124, 2005.

BELTRAN, W.A. The use of canine models of inherited retinal degeneration to test novel therapeutic approaches. Vet Ophthalmol, v.12, n.3, p.192-204, 2009.

BIRCH, G.D.; ANDERSON, M.S. Standardized full-field electroretinography. Arch Ophthalmol, v.110, p.1571-1572, 1992.

CLEMENTS, P.J.M. et al. Recent advances in understanding the spectrum of canine generalised progressive retinal atrophy. $\mathbf{J}$ Small Anim Pract, v.37, n.4, p.155-162, 1996. Disponível em: <http://onlinelibrary.wiley.com/doi/10.1111/j.1748-5827.1996. tb01950.x/abstract>. Acesso em: 9 mar. 2012 doi: 10.1111/j.17485827.1996.tb01950.x.

CÔCO, M. et al. Terapia gênica em distrofias hereditárias de retina. Arq Bras Oftalmol, v.72, n.4, p.550-566, 2009. Disponível em: $<$ http://wwwscielo.br/scielo.php?script=sci_arttext\&pid=S000427492009000400026\&In>. Acesso em: 9 mar. 2012. doi: 10.1590/ s0004-27492009000400026.

DEKOMIEN, K. et al. Progressive retinal atrophy in schapendoes dogs: mutation of newly identified CCDC 66 gene. Neurogenetics, v.11, n.2, p.163-174, 2010. Disponível em <http://www.ncbi.nlm. nih,gov/pubmed/19777273>. Acesso em: 9 mar. 2012.

DENNIS, H.M. et al. Detection of anti-lens crystallin antibody in $\operatorname{dog}$ s with and without cataracts. Vet Ophthalmol, v.6, n.4, p.321-327, 2003. Disponível em: <http://onlinelibrary.wiley.com/ doi/10.1111/j.1463-5224.2003.00314.x/abstract>. Acesso em: 9 mar. 2012. doi: 10.1111/j1463-5224.2003.00314.x.

FELIX, J.S. Teste genético para atrofia progressiva da retina. In: RIIS, R.C. Segredos em oftalmologia de pequenos animais. Porto Alegre: Artmed, 2005. p 315-323.

GELATT, K.N. Manual de oftalmologia veterinária. Barueri, São Paulo: Manole, 2003. 594p.

GRAHN, B.H.; SANDMEYER, L. Diagnostic ophthalmology. Can Vet J., v.50, n.7, p.775-776, 2009. Disponível em: <http://www. ncbi.nlm.nih.gov/pmc/articles/PMC2696715/?tool=pubmed $>$. Acesso em: 9 mar 2011.

GRANITZ, U. Descreased vision and blindness in dogs- a retrospective study. BMTW, v.107, n.9, p.295-299, 1994.

GROZDANIC, S.D et al. Differential diagnosis of retina and optic nerve diseases in dogs by pupil light reflex analysis: functional implications for SARD diagnosis. In: AMERICAN COLLEGE OF VETERINARY OPHTHALMOLOGISTS ANNUAL MEETING, 37., 2006, San Antonio, TC. Abstract... San Antonio, TC: ACVO, 2006. p.9.

GUM, G.G.et al. Physiology of the eye. In: GELTT, K.N. Vet Ophthalmol. (Ed.) 4.ed. Ames: Blackwell Publishing, 2007. p.149-182.

HONSHO, C.S. et al. Organização de uma unidade de eletrorretinografia flash em Medicina Veterinária. Cienc Rural, v.34, n.4, p.1097-1104, 2004. Disponível em: <http://www.scielo. br/scielo.php?script $=$ sci_abstract $\&$ pid $=$ S0 10384782004000400 021\&lng=pt\&nrm=iso\&tlng=pt $>$. Acesso em: 9 set. 2011. doi: http://dx.doi.org/10.1590/S0103-84782004000400021.

KARLSTAM, L. et al. A slowly progressive retinopathy in the Shetland Sheepdog. Vet Ophthalmol, v.14, n.4, p.227-238, 2011. Disponível em: <http://onlinelibrary.wiley.com>. Acesso em: 9 mar 2012. doi: 10.1111/j.1463-5224.2010.00866.x.

KOMAROMY, A.M. et al. Electroretinography in dogs and cats. Part I. Retinal morphology and physiology. CCE, v.20, n.3, p.343354, 1998.

KOMAROMY, A.M. et al. Technical issues in eletrectrodiagnostic recording. Vet Ophthalmol, v.5, n.2, p.85-91, 2002. Disponível em:<http://onlinelibrary.wiley.com/doi/10.1046/j.1463- 
5224.2002.00229.x/abstract>. Acesso em: 9 set. 2011. doi: 10.1046/j.1463-5224.2002.00229.x.

LAUS, J.L. Cirurgia del cristalino. In: HERRERA, D. Oftalmología clínica en animales de compañia. Buenos Aires: Inter-Médica, 2007. p.161-177.

LIN, C.T. et al. Canine inherited retinal degenerations: update on molecular genetics research and its clinical application. J Small Anim Pract, v.43, n.10, p.426-432, 2002. Disponível em: <http:// onlinelibrary.wiley.com/doi/10.1111/j.1748-5827.2002.tb00008.x/ abstract>. Acesso em: 9 set. 2011. doi:10.1111/j.1748-5827.2002. tb00008.x.

LUCENA, D. et al. Física e aparellhagem. In: YUGAR, J. Ecografia ocular: uma abordagem didática. 2.ed. Rio de Janeiro: Cultura Médica, Guanabara Koogan, 2009. p.1-15.

MAEHARA, S. et al. The effects of cataract stage, lens-induced uveitis and cataract removal on ERG in dogs with cataract. Vet Ophthalmol, v.10, n.5, p.308-312, 2007. Disponível em: <http:// onlinelibrary.wiley.com/doi/10.1111/j.1463-5224.2007.00559.x/ abstract>. Acesso em: 9 set. 2011. doi: 10.1111/j.14635224.2007.00559.x.

MELLERSH, C. DNA testing and domestic dogs. Mamm Genome, v.23, n.1-2, p.109-123, 2012. Disponível em: <htto:// wwwncbi.nlm.nih.gov/pubmed/21923821>. Acesso em: 9 mar. 2012. doi: 10/1007/s00335-001-9365-z.

MILLICHAMP, N.J. Retinal degeneration in the dog and cat. Vet Clin North Am: Small Anim Pract, v.20, n.3, p.799-835, 1990.

MIYADERA, K. et al. Genetic and phenotypic variations of inherited retinal diseases in dogs: the power of within- and across- breed studies. Mamm Genome, v.23, n.1-2, p.4061, 2012. Disponível em: <http://www.ncbi.nlm.nih.gov/ pubmed/22065099>. Acesso em: 9 de mar. 2012.

MORIMOTO, T. et al. Chronic implantantion of newly developed suprachoroidal-transretinal stimulation prosthesis in dogs. IOVS, v.52, n.9, p.6785-6792, 2011. Disponível em: <http://www.iovs. org/content/52/9/6785.long>. Acesso em: 9 mar. 2012. doi: 10.1167/iovs. 10-6971.

MOWAT, F.M. et al. Retinal transduction efficiency and speed of expression of AAV vectors with engineered capsid mutation in the dog. In: AMERICAN COLLEGE OF VETERINARY OPHTHALMOLOGISTS ANNUAL MEETING, 42., 2011, Hilton Head, SC, USA. Abstract... Hilton Head, SC. ACVO, 2011. p.4.

NAKAJIMA, Y. et al. Coenzyme Q10 protects retinal cells against oxidative stress in vitro and in vivo. Brain Res, v.1226, p.226-233, 2008. Disponível em: <http://www.sciencedirect.com/science/ article/pii/S0006899308014327>. Acesso em: 09 mar. 2012. doi: 10.1016/j.brainres.2008.06.026.

NARFSTRÖM, K.; EKESTEN, B. Electroretinographic evaluation of Papillons with and without hereditary retinal degeneration. Am J Vet Res, v.59, n.2, p.221-226, 1998.

NARFSTRÖM, K. Electroretinography in veterinary medicine easy or accurate? Vet Ophthalmol, v.5, n.4, p.249-251, 2002. Disponível em: <http://onlinelibrary.wiley.com/doi/10.1046/ j.1463-5224.2002.00252.x/abstract>. Acesso em: 9 set. 2011. doi: 10.1046/j.1463-5224.2002.00252.x.

NARFSTRÖM, K. et al. Characterization of feline hereditary retinal dystrophies using clinical, functional, structural and molecular genetic studies. Vet Ophthalmol, v.2011, up.1, p.3036, 2011a.

NARFSTRÖM, K. et al. The domestic cat as large animal model for characterization of disease and therapeutic intervention in hereditary retinal blindness. J Ophthalmol, v.2011, p.1-8, 2011b. Disponível em: <http: //www.ncbi.nlm.nih.gov/pmc/articles/ PMC3090773/?tool=pubmed $>$ Acesso em: 9 mar. 2012. doi: $10.1155 / 2011 / 906943$.

OFRI, R. Clinical electrophysiology in veterinary ophthalmologythe past, present and future. Doc Ophthalmol, v.104, n.1, p.5-16, 2002. Disponível em: <http://www.springerlink. com/content/cwpd21v2pga44gr9/>. Acesso em: 9 set. 2011. doi:10.1023/A:1014463514302.

PETERSEN-JONES, S.M. A review of research to elucidate the causes of the generalized progressive retinal atrophies. Vet $\mathbf{J}$, n.155, p.5-18, 1998.

QUINZE, R.S. Avaliação ultra-sonográfica do segmento posterior de olhos de cães diabéticos e não diabéticos portadores de catarata. 2005. 119f. Dissertação (Mestrado em Cirurgia) Faculdade de Medicina Veterinária e Zootecnia, Universidade de São Paulo, SP.

RIIS, R.C. Degenerações da retina. In: Segredos em oftalmologia de pequenos animais. Porto Alegre: Artmed, 2005. p.294-305.

SAFATLE, A.M.V. et al. Importância do eletrorretinograma de campo total (Full field ERG) em cães da raça Cocker Spaniel Inglês portadores de catarata. Pesq Vet Bras, v.30, n.2, p.149-154, 2010a. Disponível em: <http://www.scielo.br/scielo.php?pid=S0100736X2010000200009\&script=sci_arttext $>$. Acesso em: 25 out. 2010. doi: 10.1590/S0100-736X2010000200009.

SAFATLE, A.M.V. et al. Determinação dos valores normais do eletrorretinograma de campo total em cães da raça Poodle portadores de catarata de acordo com a faixa etária. Cienc Rural, v.40, n.3, p.587-593, 2010b. Disponível em: <http://www. scielo.br/scielo.php?script=sci_arttext\&pid=S0103847820100 $00300014 \& \operatorname{lng}=$ pt\&nrm=iso $>$. Acesso em: 25 out. 2010. doi: 10.1590/S0103-84782010000300014.

SANGIOVANNI, J.P.; CHEW, E.Y. The role of omega-3 longchain polyunsaturated fatty acids in health and disease of the retina. Prog Retin Eye Res, n.24, p.87-138, 2005.

SLATTER, D. Fundamentos de oftalmologia veterinária. 3.ed. São Paulo: Roca, 2005. 686p.

TUNTIVANICH, $\mathrm{N}$. et al. Characterization of a canine modelo $\mathrm{f}$ autosomal recessive retinitis pigmentosa due to a PDE6A mutation. IOVS, v.50, n.2, p.801-813, 2009. Disponível em: <http://www. iovs.org/content/50/2/801.long>. Acesso em: 9 mar. 2012. doi: $10.1167 /$ iovs.08-2562.

TZEKOV, R.; ARDEN, G.B. The electroretinogram in diabetic retinopathy. Surv Ophthalmol, v.44, n.1, p.53-60, 1999.

ZANGERL, B. et al. Identical mutation in a novel retinal gene causes progressive rod-cone degeneration in dogs and retinitis 
pigmentosa in humans. Genomics, v.88, n.5, p.551-563, 2006. Disponível em: <http://www.merytyme.se/PRA/ZangerlGenomics-2006[1].pdf>. Acesso em: 10 set. 2011. doi: 10.1016/j. ygeno.2006.07.007

WEICHSLER, N. Exame del ojo y anexos. In: HERRERA, D. Oftalmología clínica en animales de compañia. Buenos Aires: Inter-Médica, 2007. p.33-50.
WEICHSLER, N.; HERRERA, D. Electrorretinografia: uso clinico. In: HERRERA, D. Oftalmología clínica en animales de compañia. Buenos Aires: Inter-Médica, 2007. p.73-83.

YOGO, T. et al. Clinical manifestation of canine blindness as presumed by PRA Japan (653 cases,2005-2009). In: ANNUAL MEETING OF THE AMERICAN COLLEGE OF VETERINARY OPHTHALMOLOGISTS, 42., 2011, Hilton Head, SC, USA. Abstracts... Hilton Head, SC ACVO, 2011. p.3. 